\title{
Association of FOXF2 gene polymorphisms with ischemic stroke Association of FOXF2 gene polymorphisms with ischemic stroke in Chinese Han population
}

\author{
Chang-He Shi ${ }^{1, *}$, Mi-Bo Tang ${ }^{1, *}$, Shao-Hua Li ${ }^{1, *}$, Zhi-Jie Wang ${ }^{1}$, Xin-Jing Liu ${ }^{1}$, Lu \\ Zhao $^{1}$, Yuan Gao ${ }^{1}$, Yu-Sheng Li ${ }^{1}$, Shi-Lei Sun ${ }^{1}$, Jun $\mathbf{W u}^{1}$, Bo Song ${ }^{1}$ and $\mathrm{Yu}-\mathrm{Ming} \mathrm{Xu}^{1}$ \\ ${ }^{1}$ Department of Neurology, The First Affiliated Hospital of Zhengzhou University, Zhengzhou University, Zhengzhou 450000, \\ Henan, China \\ "These authors contributed equally to this work
}

Correspondence to: Yu-Ming Xu, email: xuyuming@zzu.edu.cn

Bo Song, email: songbo76@sina.com

Keywords: FOXF2, single nucleotide polymorphism, ischemic stroke, large artery atherosclerotic stroke, small vessel disease stroke

Received: June 21, $2017 \quad$ Accepted: September 08, $2017 \quad$ Published: September 23, 2017

Copyright: Shi et al. This is an open-access article distributed under the terms of the Creative Commons Attribution License 3.0 (CC BY

3.0), which permits unrestricted use, distribution, and reproduction in any medium, provided the original author and source are credited.

\section{ABSTRACT}

Recently, a novel locus at chromosome 6p25 (rs12204590, near FOXF2) associated with an increased risk of stroke in European populations was identified. However, whether polymorphisms in FOXF2 are also associated with the incidence of ischemic stroke in other populations remains unknown. In this case-control study, 803 Chinese Han patients with ischemic stroke and 803 matched control individuals were enrolled. Four tag SNPs and rs12204590 located in or near FOXF2 were selected, and the associations between genotypes/alleles and ischemic stroke were analyzed. In our study, we did not detect an association between the previously reported locus rs12204590 and ischemic stroke. By the genotype analysis, a novel SNP rs1711972, near FOXF2, was observed to be associated with an increased risk of ischemic stroke(CA genotype, adjusted $O R=1.35 ; 95 \% \mathrm{CI}, 1.07$ to 1.70 ), but not significantly after Bonferroni corrections for multiple tests. However, in the subgroup analysis, we discovered that rs1711972 was associated with an increased risk of large-artery atherosclerotic stroke in the additive model $(P=0.020$; CA genotype, adjusted OR $=1.50 ; 95 \% C I, 1.09$ to 2.07$)$ and dominant model $(P=0.010 ; O R=1.47 ; 95 \% C I$, 1.09 to 1.99). Collectively, these results indicate that a novel SNP near FOXF2 may influence the risk of large-artery atherosclerotic stroke in Chinese Han population.

\section{INTRODUCTION}

Stroke is the leading neurological cause of death and long-term disability worldwide [1,2]. In China, millions of people suffer from stroke, and there are approximately 2.5 million new cases of patients with stroke and 7.5 million stroke survivors each year [3,4]. Although the various risk factors underlying this critical pathological condition have been identified in different geographic regions $[5,6]$, the genetic background has been proposed as a possible cause and promoting factor for the occurrence of irregularity in the risk of stroke among ethnic populations [7]. Therefore, the other genetic loci that are associated with the susceptibility to stroke should be identified in these populations.

Risk loci associated with stroke and its subtypes have been identified in several genes $[8,9]$ such as
PITX2, ZFHX3, HDAC9, NINJ2, ABO, APOE and PMF1 $[3,10-17]$. Recently, a novel locus at chromosome 6p25 (rs12204590, near FOXF2) has been observed to be associated with an increased risk of stroke in European populations [18]. The FOXF2 gene is located in chromosome 6p25.3. It has been revealed that chromosome 6p25.3 is associated with an increase in the appearance of white matter hyperintensities in the general population [18]. FOXF2 is first expressed in the neural crest cells, and in mice, it regulates the pathways that are involved in the differentiation of mural cells (pericytes and vascular smooth muscle cells), including the PDGF- $\beta$ and serum response factor pathways [19]. FOXF2 is also required for the development of the blood-brain barrier [20]. The conditional deletion of FOXF2 in adult mice led to the development of cerebral infarction, reactive gliosis, 
and cerebral microhemorrhage [18]. Patients with rare segmental deletions of FOXF2 also exhibited an increased appearance of white matter hyperintensities. As large-artery atherosclerotic (LAA) stroke and small-vessel disease (SVD)-related stroke are the most pervasive subtypes in the Chinese Han population [21], and increasing evidence has revealed that the genetic risks vary depending on the subtypes of ischemic stroke [22], it is important to determine whether the variants in or near FOXF2 are associated with the increased risk of ischemic stroke and its subtypes.

To investigate the possible role of rs12204590 and other new loci in or near FOXF2 that are associated with ischemic stroke, a case-control study of 803 cases and 803 controls was performed.

\section{RESULTS}

\section{Clinical characteristics}

As shown in Table 1, there was no significant difference in gender $(P=0.166)$ and age $(P=0.057)$ between the patients and controls. The results for the prevalence of hyperlipidemia $(P=0.583)$ and smoking $(P=0.124)$ were also similar. Conversely, there was a significant deviation with respect to the history of hypertension $(P<0.01)$ and diabetes mellitus (DM) $(P<0.01)$ revealed between the patient and control groups. In the subsequent analyses, therefore these confounding factors (age, sex, hypertension, DM, hyperlipidemia, and smoking) were adjusted for to estimate the effect of these SNPs on the susceptibility to ischemic stroke.

\section{Association of SNP with ischemic stroke}

All the selected SNPs were in Hardy-Weinberg equilibrium $(P>0.05)$ in the control group (Table 2$)$. The univariate analysis indicated that there were significant differences in allelic frequencies of the rs1711972 A $>C$ polymorphism between the groups $(P=0.014$; OR $=1.22$; $95 \%$ CI, 1.04 to 1.42 ). The dominant-effect model also indicated that the rs1711972 locus was associated with an increased risk of ischemic stroke (CC/CA vs. AA, $P=0.011$; OR $=1.34 ; 95 \% \mathrm{CI}, 1.07$ to 1.67$)$. The frequencies of the $\mathrm{AA}, \mathrm{CA}$ and $\mathrm{CC}$ genotypes in the patients were $50.44 \%, 41.72 \%$, and $7.85 \%$ respectively, and in the controls, their frequencies were $56.78 \%$, $36.81 \%$, and $6.41 \%$ respectively (Table 3 ). The CA genotype of rs 1711972 remained associated with an increased risk of ischemic stroke in the additive model $(\mathrm{OR}=1.35 ; 95 \% \mathrm{CI}, 1.07$ to 1.70$)$; However, there was no significant association after the correction for multiple tests $\left(P^{\text {corr }}=0.019\right)$. According to the Hosmer-Leme show goodness-of-fit test, this model was well calibrated $(P=0.700$ for rs 1711972). The other four selected SNPs showed no detectable association with ischemic stroke in this study.

\section{Subgroup analysis}

To explore the effect of SNPs on the risk of the subtypes of stroke, the subjects were stratified by the TOAST subtypes. As shown in Table 4, the univariate analyses revealed significant deviations in the genotype frequencies of rs 1711972 between the patients with LAA stroke and the healthy controls $(P=0.020)$. Multivariate logistic regression analysis, which was adjusted for the aforementioned confounding factors, demonstrated that the CA genotype of rs1711972 remained associated with the increased risk of LAA stroke $(\mathrm{OR}=1.50 ; 95 \% \mathrm{CI}$, 1.09 to 2.07). The frequencies of the AA, CA, and $\mathrm{CC}$ genotypes were $47.67 \%, 42.79 \%$, and $9.54 \%$ respectively, in the patients, and $57.21 \%, 34.88 \%$, and $7.91 \%$, respectively, in the controls. A significant association with the increased risk of LAA stroke remained for the CA genotype after the correction for multiple tests $\left(P^{\text {corr }}=0.008\right) . P=0.010$ for the allelic distribution of rs 1711972 and $P=0.033$ for that of rs41300825 in association with LAA stroke. The dominant-effect model revealed that the $\mathrm{rs} 1711972$ locus (CC/CA vs. AA, $P=0.010$; OR $=1.47 ; 95 \% \mathrm{CI}, 1.09$ to 1.99 ) was associated with the increased risk of LAA stroke, and the rs41300825 locus (CC/CG vs. GG, $P=0.038$; OR $=0.68$; $95 \% \mathrm{CI}, 0.47$ to 0.98 ) was associated with a decreased risk of LAA stroke. The results of the Hosmer-Leme show goodness-of-fit test were $P=0.176$ for rs 1711972 , and $P=0.105$ for rs41300825. As shown in Table 5, no association between the involved SNPs and the risk of SVD stroke was detected.

\section{Haplotype and LD analyses}

The LD analysis revealed a block of LD, including three SNPs, rs41300825, rs732835, and rs910023 ( ${ }^{2}$ $=0.831$ ) (Supplementary Figure 1). In the haplotype analysis, after adjusting for age, sex, hypertension, DM, hyperlipidemia and smoking, none of the Haplotypes were observed to be associated with stroke (Table 6).

\section{MDR for SNP-SNP interactions}

The effect of the interaction between the selected SNPs on the risk of ischemic stroke was analyzed by MDR. As shown in Table 7, in the single-locus model, rs1711972 was the most probable contributing factor to susceptibility to ischemic stroke (testing accuracy = $0.5318, \mathrm{CVC}=10 / 10, P=0.420$ ); However, the results were not significant.

\section{DISCUSSION}

In this study, we identified a novel SNP, rs1711972, which was associated with the susceptibility to LAA stroke using the additive model, dominant model, and 
Table 1: Characteristics of cases and controls

\begin{tabular}{lccc}
\hline Variables & Cases $(\boldsymbol{n}=\mathbf{8 0 3})$ & Controls $(\boldsymbol{n}=\mathbf{8 0 3})$ & $\boldsymbol{P}$ value \\
\hline Age(years) & & & 0.057 \\
$\quad \geq 60$ & 393 & 355 & \\
$\quad<60$ & 410 & 448 & 0.166 \\
Sex & & & \\
$\quad$ Male & 555 & 529 & $<0.001$ \\
$\quad$ Female & 248 & 274 & \\
Hypertension & & & \\
$\quad$ No & 276 & 597 & \\
$\quad$ Yes & 527 & 206 & \\
Diabetes & & & \\
$\quad$ No & 633 & 768 & 0.583 \\
$\quad$ Yes & 170 & 35 & \\
Hyperlipidemia & & & \\
$\quad$ No & 383 & 394 & \\
$\quad$ Yes & 420 & 409 & \\
Smoking & & 583 & \\
$\quad$ No & 555 & 220 & \\
$\quad$ Yes & 248 & & \\
\hline
\end{tabular}

Table 2: Information of selected SNPs of FOXF2 gene region in a Chinese population

\begin{tabular}{lccccc}
\hline \multicolumn{1}{c}{ SNP } & Chr & Location on $\mathbf{C h r}$ & Allele & MAF(CHB) & $\boldsymbol{P}_{\text {value }}$ \\
\hline rs12204590 & 6 & 5081426 & T:A & 0.010 & 1.000 \\
rs1711972 & 6 & 6240084 & A:C & 0.244 & 0.958 \\
rs41300825 & 6 & 1391620 & G:C & 0.102 & 0.764 \\
rs732835 & 6 & 1393000 & G:C & 0.311 & 0.989 \\
rs910023 & 6 & 1394185 & G:A & 0.291 & 0.999 \\
\hline
\end{tabular}

SNP single nucleotide polymorphism, Chr chromosome, MAF minor allele frequency.

${ }^{a}$ From 1000 Genomes Project database.

${ }^{\mathrm{b}} P$ value Hardy-Weinberg equilibrium in controls.

allelic analyses. This is the first study to investigate the relationship between the SNPs in FOXF2 and ischemic stroke in Chinese Han population.

FOXF2 is located on chromosome 6p25.3, and consists of two exons and one intron spanning approximately 5-6 kb [18]. This gene encodes a forkhead box transcription factor, which is involved in the regulation of various developmental and biological processes $[23,24]$. Previous studies revealed that FOXF2 is expressed in neural crest cells, which are progenitors of cerebrovascular mural cells. Patients with segmental deletions of this gene showed the extensive, confluent appearance of white matter hyperintensities, and animal experiments showed that conditional FOXF2 mutations induced the development of cerebral infarction, microhemorrhage, and defects in the differentiation of cerebral vascular mural cells [20, 25]; Recently, a common variant, rs12204590 near FOXF2, was found to be associated with increased susceptibility to stroke.The rs 1711972 locus is located in the region between FOXQ1 and FOXF2, which contains enhancers and DNaseI hypersensitive regions. For this reason, we speculate that rs1711972 may regulate FOXF2 expression. However, the significant association of rs 12204590 with susceptibility to SVD stroke in Chinese Han population was not observed, which appears to conflict with the reports of previous studies on European populations. The discrepancy may be attributed to genetic heterogeneity due to geographic or ethnic distribution and minor variations in the allele frequencies of FOXF2 between Chinese and European populations (rs12204590, frequency of A allele in Europeans $=0.1899$, frequency of A allele in East Asians $=$ 0.0030). The relationship between SNP-SNP interactions and the risk of ischemic stroke was also analyzed by MDR. However, no significant interaction among these five SNPs was observed.

Our study had several limitations. First, there might be potential selection bias owing to the hospital-based study design. Second, the sample size was not particularly large, and certain positive results might not have been detected. Furthermore, as there are many factors that have been revealed to be associated with stroke, the biological mechanisms of the association between polymorphisms and susceptibility to ischemic stroke are not clarified yet, 
Table 3: Association between tag SNPs and risk of ischemic stroke

\begin{tabular}{|c|c|c|c|c|c|c|c|}
\hline \multicolumn{2}{|c|}{ Genotypes } & $\begin{array}{c}\text { Cases } \\
n=803\end{array}$ & $\begin{array}{c}\text { Controls } \\
n=803\end{array}$ & $P$ value & $P^{c o r r}$ & $\begin{array}{c}\text { Crude OR } \\
(95 \% \mathrm{CI})\end{array}$ & $\begin{array}{c}\text { Adjusted OR } \\
(95 \% \mathrm{CI})\end{array}$ \\
\hline \multicolumn{8}{|l|}{ rs12204590 } \\
\hline & TT & 786 & 791 & 0.351 & & 1.00 & 1.00 \\
\hline & AT & 17 & 12 & & & $1.43(0.68-3.00)$ & $1.20(0.52-2.79)$ \\
\hline & AA & 0 & 0 & & & & \\
\hline & $\mathrm{T}$ & 1589 & 1594 & 0.353 & & 1.00 & - \\
\hline & A & 17 & 12 & & & $1.70(0.34-1.48)$ & - \\
\hline $151 / 11912$ & AA & 405 & 456 & 0.037 & 1.000 & 1.00 & 1.00 \\
\hline & $\mathrm{CA}$ & 335 & 295 & & 0.019 & $1.28(1.04-1.57)$ & $1.35(1.07-1.70)$ \\
\hline & $\mathrm{CC}$ & 63 & 52 & & 0.118 & $1.36(0.92-2.01)$ & $1.32(0.85-2.05)$ \\
\hline & A & 1145 & 1207 & 0.014 & & 1.00 & - \\
\hline & $\mathrm{C}$ & 461 & 399 & & & $1.22(1.04-1.42)$ & - \\
\hline & $\mathrm{CC}+\mathrm{CA}$ & 398 & 347 & 0.011 & & $1.29(1.06-1.57)$ & $1.34(1.07-1.67)$ \\
\hline \multicolumn{6}{|l|}{ rs41300825 } & & \\
\hline & CG & 154 & 180 & & & $0.82(0.64-1.04)$ & $0.82(0.63-1.08)$ \\
\hline & $\mathrm{CC}$ & 7 & 9 & & & $0.74(0.28-2.01)$ & $0.73(0.24-2.20)$ \\
\hline & $\mathrm{G}$ & 1438 & 1408 & 0.096 & & 1.00 & - \\
\hline & $\mathrm{C}$ & 168 & 198 & & & $0.83(0.67-1.03)$ & - \\
\hline & $\mathrm{CC}+\mathrm{CG}$ & 161 & 189 & 0.091 & & $0.82(0.64-1.03)$ & $0.82(0.63-1.07)$ \\
\hline \multicolumn{8}{|l|}{ rs 732835} \\
\hline & CG & 329 & 324 & & & $1.02(0.83-1.25)$ & $1.07(0.85-1.35)$ \\
\hline & $\mathrm{CC}$ & 56 & 60 & & & $0.94(0.63-1.38)$ & $1.01(0.65-1.57)$ \\
\hline & G & 1165 & 1162 & 0.906 & & 1.00 & - \\
\hline & $\mathrm{C}$ & 441 & 444 & & & $0.99(0.85-1.16)$ & - \\
\hline & $\mathrm{CC}+\mathrm{CG}$ & 385 & 384 & 0.960 & & $1.01(0.83-1.22)$ & $1.06(0.85-1.32)$ \\
\hline rs910023 & GG & 447 & 451 & 0.980 & & 1.00 & 1.00 \\
\hline & GA & 305 & 302 & & & $1.02(0.83-1.25)$ & $1.07(0.85-1.35)$ \\
\hline & $\mathrm{AA}$ & 51 & 50 & & & $1.03(0.68-1.56)$ & $1.15(0.73-1.84)$ \\
\hline & $\mathrm{G}$ & 1199 & 1204 & 0.839 & & 1.00 & - \\
\hline & A & 407 & 402 & & & $1.02(0.87-1.20)$ & - \\
\hline & $\mathrm{AA}+\mathrm{GA}$ & 356 & 352 & 0.841 & & $1.02(0.84-1.24)$ & $1.08(0.87-1.35)$ \\
\hline
\end{tabular}

$C I$ confidence interval, $O R$ odds ratio.

${ }^{\text {a }}$ Adjusted for age, sex, hypertension, diabetes mellitus, hyperlipidemia, and smoking.

$P^{\text {corr }}$ corrected $P$ value by Bonferroni correction.

which requires additional in vitro and in vivo studies in the future.

In summary, we identified a novel FOXF2 SNP (rs1711972), which may be used as a candidate biomarker of ischemic stroke and LAA stroke in the Chinese Han population. Simultaneously, the early detection of SNPs would greatly contribute to the prevention of ischemic stroke, particularly LAA stroke. Future studies on different population groups and well-designed functional experiments are necessary to verify and extend our findings.

\section{MATERIALS AND METHODS}

\section{Ethics statement}

This study was approved by the Ethics Review Board of The First Affiliated Hospital of Zhengzhou
University (Zhengzhou, China). All the enrolled patients provided their written informed consent to participate.

\section{Study subjects}

The study enrolled 803 patients with ischemic stroke and 803 healthy controls. The patients were selected from the hospitalized patients who experienced their first-ever stroke between July 2011 and March 2016. All the patients were initially assessed for the eligibility to participate. The inclusion criteria for the patients were obtained from certain published papers and guides as follows [3, 4]: (1) Chinese Han ethnicity, (2) age of 18 years or above, (3) incidence of first-ever ischemic stroke diagnosed within 14 days. The exclusion criteria were: (1) incidence of severe heart, lung, liver, and kidney dysfunction, (2) incidence of malignancies, (3) incidence of hematologic diseases, 
Table 4: Association between tag SNPs and risk of LAA stroke

\begin{tabular}{|c|c|c|c|c|c|c|c|}
\hline Genotypes & & $\begin{array}{l}\text { Cases } \\
n=430\end{array}$ & $\begin{array}{l}\text { Controls } \\
n=430\end{array}$ & $P$ value & $P^{c o r r}$ & $\begin{array}{l}\text { Crude OR } \\
(95 \% \mathrm{CI})\end{array}$ & $\begin{array}{l}\text { Adjusted OR } \\
(95 \% \mathrm{CI})\end{array}$ \\
\hline \multicolumn{8}{|l|}{ rs12204590 } \\
\hline & TT & 422 & 424 & 0.591 & & 1.00 & 1.00 \\
\hline & AT & 8 & 6 & & & $1.34(0.46-3.89)$ & $0.87(0.27-2.78)$ \\
\hline & AA & 0 & 0 & & & & \\
\hline & $\mathrm{T}$ & 852 & 854 & 0.593 & & 1.00 & - \\
\hline & A & 8 & 6 & & & $1.37(0.46-3.87)$ & - \\
\hline \multicolumn{5}{|l|}{ rs1711972 } & 1.000 & 1.00 & 1.00 \\
\hline & $\mathrm{CA}$ & 184 & 150 & & 0.008 & $1.47(1.11-1.96)$ & $1.50(1.09-2.07)$ \\
\hline & $\mathrm{CC}$ & 41 & 34 & & 0.139 & $1.45(0.89-2.36)$ & $1.36(0.78-2.37)$ \\
\hline & A & 594 & 642 & 0.010 & & 1.00 & - \\
\hline & $\mathrm{C}$ & 266 & 218 & & & $1.34(1.07-1.62)$ & - \\
\hline & $\mathrm{CC}+\mathrm{CA}$ & 225 & 184 & 0.010 & & $1.47(1.21-1.92)$ & $1.47(1.09-1.99)$ \\
\hline rs41300825 & GG & 350 & 325 & 0.099 & & 1.00 & 1.00 \\
\hline & $\mathrm{CG}$ & 77 & 99 & & & $0.72(0.52-1.01)$ & $0.70(0.48-1.02)$ \\
\hline & $\mathrm{CC}$ & 3 & 6 & & & $0.46(0.12-1.88)$ & $0.42(0.10-1.83)$ \\
\hline & $\mathrm{G}$ & 777 & 749 & 0.033 & & 1.00 & - \\
\hline & $\mathrm{C}$ & 83 & 111 & & & $0.72(0.53-0.98)$ & - \\
\hline & $\mathrm{CC}+\mathrm{CG}$ & 80 & 105 & 0.038 & & $0.71(0.51-0.98)$ & $0.68(0.47-0.98)$ \\
\hline \multicolumn{8}{|l|}{ rs 732835} \\
\hline & GG & 236 & 220 & 0.494 & & 1.00 & 1.00 \\
\hline & CG & 165 & 182 & & & $0.85(0.64-1.12)$ & $0.91(0.67-1.24)$ \\
\hline & $\mathrm{CC}$ & 29 & 28 & & & $0.97(0.56-1.68)$ & $1.21(0.65-2.24)$ \\
\hline & $\mathrm{G}$ & 637 & 622 & 0.414 & & 1.00 & - \\
\hline & $\mathrm{C}$ & 223 & 238 & & & $0.92(0.74-1.13)$ & - \\
\hline & $\mathrm{CC}+\mathrm{CG}$ & 194 & 210 & 0.520 & & $0.87(0.66-1.13)$ & $0.94(0.70-1.27)$ \\
\hline rs910023 & GG & 248 & 238 & 0.568 & & 1.00 & 1.00 \\
\hline & GA & 155 & 169 & & & $0.89(0.66-1.17)$ & $0.95(0.70-1.31)$ \\
\hline & AA & 27 & 23 & & & $1.13(0.63-2.02)$ & $1.44(0.75-2.78)$ \\
\hline & $\mathrm{G}$ & 651 & 645 & 0.758 & & 1.00 & - \\
\hline & A & 209 & 215 & & & $0.97(0.78-1.20)$ & - \\
\hline & $\mathrm{AA}+\mathrm{GA}$ & 182 & 192 & 0.492 & & $0.91(0.70-1.19)$ & $1.01(0.74-1.36)$ \\
\hline
\end{tabular}

$C I$ confidence interval, $O R$ odds ratio.

${ }^{\text {a }}$ Adjusted for age, sex, hypertension, diabetes mellitus, hyperlipidemia, and smoking.

$P^{\text {corr }}$ corrected $P$ value by Bonferroni correction.

(4) incidence of autoimmune, inflammatory, or systematic diseases. The stroke-free control subjects were selected from local residents who underwent physical examinations in the sample hospital, and their inclusion criteria were as follows: (1) Chinese Han ethnicity, (2) age of 18 years or above, (3) no history of atherosclerotic, cardiovascular, and cerebrovascular diseases; (4) regular physical examinations.

\section{Selection of SNPs}

The acquisition of SNP data was based on the HapMap database, and tag SNPs were determined using the Haploview Software version 4.2(http://www.broadinstitute. org/haploview/haploview) [26], and selected using the following filters: (1) $\mathrm{r}^{2}=0.8$, (2) minor allele frequency
(MAF) $\geq 10 \%$, (3) Hardy-Weinberg equilibrium test $P$ value $\geq 0.05$. Finally, a total of 5 SNPs were selected for further investigation: Four were novel tag SNPs (rs1711972, rs41300825, rs732835, and rs910023), and one was the recently reported risk locus for stroke (rs12204590). Table 2 shows the chromosomal location and information on the population distribution of these SNPs. Linkage disequilibrium (LD) between the SNPs was calculated using the Haploview Software version 4.2, and is included in Supplementary Figure 1.

\section{DNA isolation and genotyping}

DNA was isolated as described previously [4]. Five milliliters $(\mathrm{ml})$ of peripheral blood was collected from 
Table 5: Association between tag SNPs and risk of SVD stroke

\begin{tabular}{|c|c|c|c|c|c|c|}
\hline Genotypes & & $\begin{array}{l}\text { Cases } \\
n=373\end{array}$ & $\begin{array}{l}\text { Controls } \\
n=373\end{array}$ & $P$ value & $\begin{array}{l}\text { Crude OR } \\
(95 \% \mathrm{CI})\end{array}$ & $\begin{array}{l}\text { Adjusted OR } \\
(95 \% \mathrm{CI})\end{array}$ \\
\hline \multicolumn{7}{|l|}{ rs 12204590} \\
\hline & TT & 364 & 367 & 0.437 & 1.00 & 1.00 \\
\hline & AT & 9 & 6 & & $1.51(0.53-4.29)$ & $1.27(0.39-4.09)$ \\
\hline & AA & 0 & 0 & & & \\
\hline & $\mathrm{T}$ & 737 & 740 & 0.178 & 1.00 & - \\
\hline & A & 9 & 6 & & $2.25(0.69-7.35)$ & - \\
\hline \multicolumn{7}{|l|}{ rs1711972 } \\
\hline & AA & 200 & 211 & 0.231 & 1.00 & 1.00 \\
\hline & CA & 151 & 132 & & $1.22(0.90-1.65)$ & $1.32(0.95-1.85)$ \\
\hline & $\mathrm{CC}$ & 22 & 30 & & $0.77(0.43-1.39)$ & $0.92(0.48-1.75)$ \\
\hline & A & 551 & 554 & 0.859 & 1.00 & 一 \\
\hline & $\mathrm{C}$ & 195 & 192 & & $1.02(0.81-1.29)$ & - \\
\hline & $\mathrm{CC}+\mathrm{CA}$ & 173 & 162 & 0.418 & $1.13(0.84-1.50)$ & $1.25(0.91-1.72)$ \\
\hline \multicolumn{6}{|l|}{ rs41300825 } & \\
\hline & GG & 292 & 279 & 0.688 & 1.00 & 1.00 \\
\hline & CG & 77 & 88 & & $0.89(0.63-1.26)$ & $0.81(0.55-1.19)$ \\
\hline & $\mathrm{CC}$ & 4 & 6 & & $0.68(0.19-2.43)$ & $0.67(0.16-2.77)$ \\
\hline & G & 661 & 646 & 0.239 & 1.00 & - \\
\hline & $\mathrm{C}$ & 85 & 100 & & $0.83(0.61-1.13)$ & 一 \\
\hline & $\mathrm{CC}+\mathrm{CG}$ & 81 & 94 & 0.262 & $0.82(0.59-1.16)$ & $0.80(0.55-1.16)$ \\
\hline \multicolumn{7}{|l|}{ rs732835 } \\
\hline & GG & 182 & 192 & 0.705 & 1.00 & 1.00 \\
\hline & $\mathrm{CG}$ & 164 & 158 & & $1.10(0.81-1.48)$ & $1.10(0.79-1.54)$ \\
\hline & $\mathrm{CC}$ & 27 & 23 & & $1.24(0.69-2.24)$ & $1.45(0.75-2.79)$ \\
\hline & G & 528 & 542 & 0.421 & 1.00 & - \\
\hline & C & 218 & 204 & & $1.10(0.88-1.40)$ & - \\
\hline & $\mathrm{CC}+\mathrm{CG}$ & 191 & 181 & 0.464 & $1.13(0.84-1.48)$ & $1.14(0.83-1.57)$ \\
\hline rs910023 & GG & 199 & 205 & 0.715 & 1.00 & 1.00 \\
\hline & GA & 150 & 149 & & $1.04(0.77-1.40)$ & $1.05(0.76-1.46)$ \\
\hline & AA & 24 & 19 & & $1.30(0.69-2.45)$ & $1,48(0.73-2.99)$ \\
\hline & G & 548 & 559 & 0.515 & 1.00 & - \\
\hline & A & 198 & 187 & & $1.08(0.86-1.36)$ & - \\
\hline & $\mathrm{AA}+\mathrm{GA}$ & 174 & 168 & 0.659 & $1.07(0.80-1.42)$ & $1.10(0.80-1.51)$ \\
\hline
\end{tabular}

$C I$ confidence interval, $O R$ odds ratio.

${ }^{\text {a }}$ Adjusted for age, sex, hypertension, diabetes mellitus, hyperlipidemia, and smoking.

Table 6: Hyplotype analysis between cases and controls

\begin{tabular}{|c|c|c|c|c|c|}
\hline HapMap block & Hyplotype $^{\mathrm{a}}$ & $\begin{array}{c}\text { Case } \\
\text { (n, frequencies) }\end{array}$ & $\begin{array}{c}\text { Control } \\
\text { (n, frequencies) }\end{array}$ & $\begin{array}{c}\text { Adjusted OR } \\
(95 \% \mathrm{CI})^{\mathrm{b}}\end{array}$ & $P$ value $^{\mathrm{b}}$ \\
\hline \multicolumn{6}{|l|}{ Block1 } \\
\hline rs41300825, rs732835,rs910023 & CGG & $170,0.105$ & $195,0.121$ & $0.86(0.69-1.07)$ & 0.173 \\
\hline rs41300825, rs732835,rs910023 & GCG & $47,0.029$ & $42,0.026$ & $1.13(0.74-1.72)$ & 0.583 \\
\hline rs41300825, rs732835,rs910023 & GGG & $987,0.612$ & $965,0.597$ & $1.07(0.93-1.23)$ & 0.379 \\
\hline rs41300825, rs732835,rs910023 & GCA & $396,0.246$ & $400,0.248$ & $0.99(0.84-1.16)$ & 0.902 \\
\hline
\end{tabular}

$C I$ confidence interval, $O R$ odds ratio

${ }^{\text {a }}$ Haplotypes with frequency less than $1 \%$ were omitted

${ }^{\mathrm{b}}$ Adjusted for age, sex, hypertension, diabetes mellitus, hyperlipidemia, and smoking. 
Table 7: SNP-SNP interactions analyzed with MDR

\begin{tabular}{lllll}
\hline Model & Bal.Acc.Cvtraining & Bal.Acc.Cv testing & CVC & $\boldsymbol{P}_{\text {value }}$ \\
\hline rs1711972 & 0.5318 & 0.5318 & $10 / 10$ & 0.420 \\
rs1711972, rs41300825 & 0.5434 & 0.5255 & $7 / 10$ & 0.513 \\
rs1711972, rs41300825, rs910023 & 0.5515 & 0.5162 & $6 / 10$ & 0.682 \\
rs1711972, rs41300825, rs732835, rs910023 & 0.5561 & 0.5118 & $6 / 10$ & 0.764 \\
\hline
\end{tabular}

$C V C$ cross-validation consistency.

${ }^{a} P$ value based on 1000 permutations.

each subject in an vacutainer tube with EDTA. Genomic DNA was extracted using a DNA isolation kit, according to the manufacturer's instructions. Genotyping was performed by the improved multiple ligation-detection reaction (iMLDR), with technical support from the Center for Human Genetics Research. For quality control and validation purposes, genotyping was repeated on $10 \%$ of the samples, and the concordance rate for the replicate samples was $100 \%$. The sequences of the primer pairs used are shown in the Supplementary Table 1.

\section{SNP-SNP interactions}

The SNP-SNP interactions were analyzed as described previously [3]. Multifactor dimensionality reduction (MDR) (version 3.0_0_2) and MDR-permutation testing ( MDRpt, version 1.0_beta_2) were adopted to evaluate the effect of the SNP-SNP interactions on the risk of developing ischemic stroke [27, 28]. Cross-validation and permutation tests were conducted to evaluate the validity of these models for predicting the risk of ischemic stroke. For multi loci models, the highest level of testing accuracy and the cross-validation consistency (CVC) were used for determining the best candidate interaction model. Furthermore, a testing accuracy level greater than 0.5 was required in the true-positive models. Statistical significance was analyzed by the implementation of 1000fold permutation testing methods, and a $P$ value less than 0.05 was considered statistically significant.

\section{Statistical analysis}

A chi-square goodness of fit test was conducted to determine the Hardy-Weinberg equilibrium of the frequency distribution of each SNP in the control group (Table 2). Chi-square tests were also conducted to compare the differences in categorical covariates between the patients and controls. Logistic regression analysis was performed to evaluate the association of each SNP with the risk of ischemic stroke and its subtypes. The Hosmer-Leme show goodness of fit test was performed to assess the calibration of the logistic regression model. For single comparison, a $P$ value $<0.05$ was considered statistically significant. For multiple comparisons, the Bonferroni correction was adopted for correcting the $P$ values. A $P$ value $<0.05 /$ number of comparisons was considered statistically significant. The analysis of linkage disequilibrium (LD) was performed, and haplotype blocks were identified using Haploview v4.2, then the haplotypes were reconstructed using the PHASE software v2.1; the effect of the potential interactions between these five tSNPs on susceptibility to ischemic stroke was analyzed by MDR. The statistical analyses were conducted using IBM SPSS Statistics version 22.0 (Armonk, NY, USA: IBM Corp.).

\section{Abbreviations}

Large artery atherosclerotic (LAA), Small vessel disease (SVD), Cross-validation consistency (CVC), Minor allele frequency (MAF), Linkage disequilibrium (LD).

\section{Author contributions}

Chang-he Shi, Yu-ming Xu and Bo Song conceived and designed the experiments. Mi-bo Tang, Shao-hua Li, Zhi-jie Wang, Xin-jing Liu and Lu Zhao performed the experiments. Yuan Gao, Yu-sheng Li, Shi-Lei Sun, Jun Wu analyzed the data. Chang-he Shi and Bo Song wrote the manuscript.

\section{ACKNOWLEDGMENTS}

The work was supported by the grants from the National Natural Science Foundation of China grant 81530037 and 81471158 (to Dr Yuming Xu), the National Natural Science Foundation of China grant U1404311 (to Dr Changhe Shi) and the National Natural Science Foundation of China grant 81571158 (to Dr Bo Song).

\section{CONFLICTS OF INTEREST}

No conflicts of interest.

\section{REFERENCES}

1. Johnston SC, Mendis S, Mathers CD. Global variation in stroke burden and mortality: estimates from monitoring, surveillance, and modelling. Lancet Neurol. 2009; 8:345-354.

2. Matarín M, Brown WM, Scholz S, Simón-Sánchez J, Fung HC, Hernandez D, Gibbs JR, De Vrieze FW, Crews C, Britton A, Langefeld CD, Brott TG, Brown RD Jr, et al. 
A genome-wide genotyping study in patients with ischaemic stroke: initial analysis and data release. Lancet Neurol. 2007; 6:414-420.

3. Zhang H, Zhang Z, Zhang J, Xu L, Ye Z, Hao Y, Cai B, Zhou S, Liu K, Sun L, Sun W, Zhang Y, Cai H, et al. Fine-Mapping of ABO Gene Identifies Two Novel SNPs Associated with Large Artery Atherosclerotic Stroke in a Chinese Han Population. Mol Neurobiol. 2017; 54:2107-13.

4. Zhang H, Zhai Q, Zhang Z, Cai B, Cai H, Zhou S, Sun L, Xie Y, Kong D, Xu Z, Yuan K, Zi W, Liu X, Xu G. Association of GWAS-Supported Variants rs556621 on Chromosome 6p21.1 with Large Artery Atherosclerotic Stroke in a Southern Chinese Han Population. Neuromolecular Med. 2017; 19:94-100.

5. Hankey GJ. Stroke. Lancet. 2017; 389:641-654.

6. Marshall IJ, Wang Y, Crichton S, McKevitt C, Rudd AG, Wolfe CD. The effects of socioeconomic status on stroke risk and outcomes. Lancet Neurol. 2015; 14:1206-1218.

7. Humphries SE, Morgan L. Genetic risk factors for stroke and carotid atherosclerosis: insights into pathophysiology from candidate gene approaches. Lancet Neurol. 2004; 3:227-235.

8. Zhang X, Cao X, Xu X, Li A, Xu Y. Correlation between the $-1562 \mathrm{C} / \mathrm{T}$ polymorphism in the matrix metalloproteinase- 9 gene and hemorrhagic transformation of ischemic stroke. Exp Ther Med. 2015; 9:1043-1047.

9. Zhao J, Zheng L, Fei Q, Fu Y, Weng Y, Wu H, Li H, Jun $\mathrm{Q}$, Shao J, Xu Y. Association of thromboxane A2 receptor gene polymorphisms with cerebral infarction in a Chinese population. Neurol Sci. 2013; 34:1791-1796.

10. Söderholm M, Almgren P, Jood K, Stanne TM, Olsson M, Ilinca A, Lorentzen E, Norrving B, Engström G, Melander O, Jern C, Lindgren A. Exome array analysis of ischaemic stroke: results from a southern Swedish study. Eur J Neurol. 2016; 23:1722-28.

11. Pulit SL, McArdle PF, Wong Q, Malik R, Gwinn K, Achterberg S, Algra A, Amouyel P, Anderson CD, Arnett DK, Arsava EM, Attia J, Ay H, et al, and NINDS Stroke Genetics Network (SiGN), and International Stroke Genetics Consortium (ISGC). Loci associated with ischaemic stroke and its subtypes ( $\mathrm{SiGN}$ ): a genome-wide association study. Lancet Neurol. 2016; 15:174-84.

12. Gardener H, Beecham A, Cabral D, Yanuck D, Slifer S, Wang L, Blanton SH, Sacco RL, Juo SH, Rundek T. Carotid plaque and candidate genes related to inflammation and endothelial function in Hispanics from northern Manhattan. Stroke. 2011; 42:889-896.

13. Ikram MA, Seshadri S, Bis JC, Fornage M, DeStefano AL, Aulchenko YS, Debette S, Lumley T, Folsom AR, van den Herik EG, Bos MJ, Beiser A, Cushman M, et al. Genomewide association studies of stroke. N Engl J Med. 2009; 360:1718-1728.

14. Gudbjartsson DF, Holm H, Gretarsdottir S, Thorleifsson G, Walters GB, Thorgeirsson G, Gulcher J, Mathiesen EB, Njølstad I, Nyrnes A, Wilsgaard T, Hald EM, Hveem K, et al. A sequence variant in ZFHX3 on 16q22 associates with atrial fibrillation and ischemic stroke. Nat Genet. 2009; 41:876-878.

15. Bellenguez C, Bevan S, Gschwendtner A, Spencer CC, Burgess AI, Pirinen M, Jackson CA, Traylor M, Strange A, Su Z, Band G, Syme PD, Malik R, et al, and International Stroke Genetics Consortium (ISGC), and Wellcome Trust Case Control Consortium 2 (WTCCC2). Genome-wide association study identifies a variant in HDAC9 associated with large vessel ischemic stroke. Nat Genet. 2012; 44:328-333.

16. Williams FM, Carter AM, Hysi PG, Surdulescu G, Hodgkiss D, Soranzo N, Traylor M, Bevan S, Dichgans M, Rothwell PM, Sudlow C, Farrall M, Silander K, et al, and EuroCLOT Investigators, and Wellcome Trust Case Control Consortium 2, and MOnica Risk, Genetics, Archiving and Monograph, and MetaStroke, and International Stroke Genetics Consortium. Ischemic stroke is associated with the ABO locus: the EuroCLOT study. Ann Neurol. 2013; 73:16-31.

17. Carpenter AM, Singh IP, Gandhi CD, Prestigiacomo CJ. Genetic risk factors for spontaneous intracerebral haemorrhage. Nat Rev Neurol. 2016; 12:40-49.

18. Chauhan G, Arnold CR, Chu AY, Fornage M, Reyahi A, Bis JC, Havulinna AS, Sargurupremraj M, Smith AV, Adams HH, Choi SH, Pulit SL, Trompet S, et al, and Neurology Working Group of the Cohorts for Heart and Aging Research in Genomic Epidemiology (CHARGE) Consortium, the Stroke Genetics Network (SiGN), and the International Stroke Genetics Consortium (ISGC). Identification of additional risk loci for stroke and small vessel disease: a meta-analysis of genome-wide association studies. Lancet Neurol. 2016; 15:695-707.

19. Bolte C, Ren X, Tomley T, Ustiyan V, Pradhan A, Hoggatt A, Kalin TV, Herring BP, Kalinichenko VV. Forkhead box F2 regulation of platelet-derived growth factor and myocardin/serum response factor signaling is essential for intestinal development. J Biol Chem. 2015; 290:7563-7575.

20. Reyahi A, Nik AM, Ghiami M, Gritli-Linde A, Ponten F, Johansson BR, Carlsson P. Foxf2 Is Required for Brain Pericyte Differentiation and Development and Maintenance of the Blood-Brain Barrier. Dev Cell. 2015; 34:19-32.

21. Liu M, Wu B, Wang WZ, Lee LM, Zhang SH, Kong LZ. Stroke in China: epidemiology, prevention, and management strategies. Lancet Neurol. 2007; 6:456-464.

22. Munshi A, Das S, Kaul S. Genetic determinants in ischaemic stroke subtypes: seven year findings and a review. Gene. 2015; 555:250-259.

23. Lehmann OJ, Sowden JC, Carlsson P, Jordan T, Bhattacharya SS. Fox's in development and disease. Trends Genet. 2003; 19:339-344.

24. Carlsson P, Mahlapuu M. Forkhead transcription factors: key players in development and metabolism. Dev Biol. 2002; 250:1-23.

25. Wardlaw JM, Smith C, Dichgans M. Mechanisms of sporadic cerebral small vessel disease: insights from neuroimaging. Lancet Neurol. 2013; 12:483-497. 
26. Barrett JC, Fry B, Maller J, Daly MJ. Haploview: analysis and visualization of LD and haplotype maps. Bioinformatics. 2005; 21:263-265.

27. Ritchie MD, Hahn LW, Roodi N, Bailey LR, Dupont WD, Parl $\mathrm{FF}$, Moore JH. Multifactor-dimensionality reduction reveals high-order interactions among estrogen-metabolism genes in sporadic breast cancer. Am J Hum Genet. 2001; 69:138-147.
28. Sharma KL, Rai R, Srivastava A, Sharma A, Misra S, Kumar A, Mittal B. A multigenic approach to evaluate genetic variants of PLCE1, LXRs, MMPs, TIMP, and CYP genes in gallbladder cancer predisposition. Tumour Biol. 2014; 35:8597-8606. 